\section{EXATASE TECNOLÓGICAS}

V.4 • N.1 2020 - Fluxo Contínuo

ISSN Digital: 2359-4942

ISSN Impresso: 2359-4934

DOI: 10.17564/2359-4942.2020v4n1p116-129

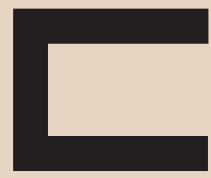

开 $N$ 立同(

CIENTÍFICAS

\title{
AVALIAÇÃO DE DADOS HISTÓRICOS SOBRE A QUALIDADE DO ATENDIMENTO NO SETOR ELÉTRICO DE ALAGOAS
}

EVALUATION OF HISTORICAL DATA ON THE QUALITY OF SERVICE IN THE ELECTRIC SECTOR OF ALAGOAS

EVALUACIÓN DE DATOS HISTÓRICOS SOBRE CALIDAD DE SERVICIO EN EL SECTOR ELÉCTRICO DE ALAGOAS

Gilvan Augusto Rolemberg Gama Cabral ${ }^{1}$ Arthur Nunes de Castro Oliveira ${ }^{2}$

Guilherme Miguel de Souza Menezes ${ }^{3}$

Matheus Ferraz de Maia Bastos Bizerra ${ }^{4}$

Walter Winícius Oliveira Menezes ${ }^{5}$

Vittória Andressa Wanderley Nelo $^{6}$

Danielle Freitas Santos Marinho ${ }^{7}$

\section{RESUMO}

Com o passar dos anos a influência das informações com propósito de alavancagem empresarial tem se tornado mais forte. A cada momento novas tecnologias enchem os mais diversos setores, a competitividade dinâmica empresarial é o principal fator dessa busca por melhorias, para alcançar novos patamares de níveis de atendimento, sendo necessário ter maior entendimento dos pontos fortes e fracos do seu produto ou serviço. A satisfação do seu cliente continua sendo um indicador primordial para garantir a qualidade do serviço e consequentemente manter seu espaço em um cenário ativo e exigente. 0 presente estudo objetiva avaliar os dados relativos a qualidade de atendimento de uma concessionária de energia elétrica do estado de Alagoas. Para tanto, o uso de dados históricos foi o ponto de partida da análise. Permitiu-se ainda, estabelecer um comparativo regional desse cenário. Tais indicadores devem ser utilizados como ferramenta importante no processo decisório, visando a melhoria do atendimento ao cliente final.

\section{PALAVRAS-CHAVE}

Atendimento ao Cliente. Indicadores. Setor de Energia Elétrica. 


\section{ABSTRACT}

Over the years, the influence of information for the purpose of business leverage has become stronger. At every moment new technologies fill the most diverse sectors, dynamic business competitiveness is the main factor in this search for improvements, to reach new levels of service levels, requiring a greater understanding of the strengths and weaknesses of your product or service. Your customer's satisfaction continues to be a primary indicator to guarantee the quality of the service and consequently maintain your space in an active and demanding scenario. The present study aims to evaluate the data related to the quality of service of an electric utility in the state of Alagoas. For that, the use of historical data was the starting point of the analysis. It was also allowed to establish a regional comparison of this scenario. Such indicators should be used as an important tool in the decision-making process aimed at improving the service to the final customer.

\section{KEYWORDS}

Customer service. Indicators. Electricity sector.

\section{RESUMEN}

Con el paso de los años, la influencia de la información con fines de apalancamiento empresarial se ha vuelto más fuerte. En cada momento las nuevas tecnologías llenan los más diversos sectores, la competitividad empresarial dinámica es el factor principal en esta búsqueda de mejoras, para alcanzar nuevos niveles de servicio, requiriendo un mayor conocimiento de las fortalezas y debilidades de su producto o servicio. La satisfacción de su cliente sigue siendo un indicador primordial para garantizar la calidad del servicio y en consecuencia mantener su espacio en un escenario activo y exigente. El presente estudio tiene como objetivo evaluar los datos relacionados con la calidad del servicio de una empresa eléctrica en el estado de Alagoas. Para eso, el uso de datos históricos fue el punto de partida del análisis. También se permitió establecer una comparación regional de este escenario. Estos indicadores deben utilizarse como una herramienta importante en el proceso de toma de decisiones orientadas a mejorar el servicio al cliente final.

\section{PALABRAS CLAVE}

Atención al cliente. Indicadores. Sector eléctrico. 


\section{INTRODUÇÃO}

Devido ao avanço da indústria tecnológica em conjunto com a globalização, a velocidade de acesso à informação pode desencadear vantagens competitivas para quem as utiliza de maneira producente. No âmbito corporativo, a ciência dos dados é um fator decisivo para melhoria contínua de serviços e produtos, sejam estes de aspectos financeiros, econômicos, sociais, estruturados ou não, as informações geradas por eles podem agregar no conhecimento, melhorando o direcionamento dos investimentos monetários e/ou intelectuais.

A energia elétrica é sem sombra de dúvidas um dos principais elementos contribuintes para o desenvolvimento tecnológico nas atividades produtivas, por meio dela é possível utilizar incontáveis ferramentas, acessórios, máquinas e objetos que facilitam nossas vidas e dão vida a criatividade e inovação. Tolmasquim (2012) cita que se tratando da sustentabilidade econômica de um local, um dos elementos mais impactantes para esse quesito é o potencial de distribuição logística da energia, ou seja, a capacidade de transmissão energética pelos mais diversos polos regionais, sendo um indicador fundamental quando tratamos de desenvolvimento sustentável na região.

Atualmente o sistema de distribuição elétrico brasileiro é formado por diversos processos com fins de obtenção e preparação da energia para então chegar na utilização pelo consumidor, as concessionárias de energia são as organizações destinadas a garantir provisões elétricas ao cliente final, estas necessitam garantir níveis excelentes de qualidade no serviço para garantir o funcionamento domiciliar e comercial da região.

Dessa forma, é imprescindível que o foco logístico de atendimento da concessionária local esteja antenado e direcionado de forma correta, assim é possível manter pontos positivos e modificar negativos, agindo assertivamente no desempenho social, econômico e ambiental.

Este estudo visa analisar dados relativos a qualidade do atendimento da empresa responsável pelo fornecimento e manutenção de energia elétrica para os residentes do estado de Alagoas, além disso, permitirá a geração de informações comparativas com o grau de atendimento alcançados pela região Nordeste do país.

\section{REFERENCIAL TEÓRICO}

\subsection{SETOR DE ENERGIA ELÉTRICA}

A energia elétrica desde sua descoberta e controle no século XIX se tornou um dos principais bens essenciais para o avanço econômico e social no mundo, usada em iluminação, tração e movimento, aquecimento e outras finalidades necessárias. A energia elétrica surgiu como uma solução para o desenvolvimento das sociedades, essas cada vez mais tecnológicas (Falcão et al., 2019; Leite et al., 2017).

Romara (2005) afirma que o setor elétrico brasileiro passou por intensas mudanças nos últimos períodos, onde até a década de 1970 estava desenvolvido um modelo de mercado estatal, na qual as 
funções administrativas e de distribuição de energia estavam sob responsabilidade do Estado, porém ao longo dos anos houve alteração significativa nessa perspectiva de mercado, principalmente a partir da década de 1990, direcionando as principais obrigações gerenciais para a iniciativa privada.

Assim, como as mudanças do modelo de negócio, Rego (2012) destaca a contribuição desse setor para o avanço econômico e social, em que nos últimos 40 anos houve um aumento significativo no consumo de energia por habitante, visto que em 1960 o número de domicílios atendidos representava 38\%, em 1990 este número aumentou para 90\%. Em um estudo mais recente realizado pelo Instituto Brasileiro de Estatística e Geografia (IBGE, 2010), o Brasil possuía até o ano de 2010, 57.324.185 domicílios particulares nas quais 728.512 não possuem energia elétrica, representando cerca de $98,7 \%$ de unidades com energia elétrica.

Assim sendo, se faz necessária a transformação das energias obtidas de diversas fontes em energia elétrica e o seu transporte até os consumidores finais. A Agência Nacional de Energia elétrica (ANEEL, 2016) explica que a principal fonte de geração no Brasil é a hidrelétrica, que correspondem a $62 \%$ da capacidade instalada em operação no país, seguido pelas termelétricas que são responsáveis por $28 \%$ e o restante oriundo das usinas eólicas e importações de outros países.

Falcão et al. (2019) explica o processo produtivo da cadeia de suprimento do setor energético brasileiro que em sua maioria se obtém a partir dos recursos hídricos. As empresas que geram a energia elétrica a obtêm por meio da transformação da energia hidráulica em energia elétrica e assim a disponibilizam para o sistema de transmissão, por sua vez as empresas transmissoras se responsabilizam por transportar essa eletricidade por uma grande distância até as empresas distribuidoras que a partir disto entregam para os consumidores finais.

\subsection{INDICADORES DE QUALIDADE}

A constante evolução tecnológica, a grande quantidade de informações e o aumento da concorrência exigem com que as empresas tenham que adotar um sistema de melhoria contínua para seguirem firmes no mercado. Um dos pontos essenciais para o sistema de melhoria contínua é o estabelecimento de indicadores de qualidade que sejam capazes de refletir o desempenho de determinado processo (CARREGARO, 2003).

Fernandes (2004) define que a função básica de um indicador é representar, de forma simples e objetiva, determinado processo em que se deseja avaliar. Desta forma, o resultado de um indicador pode ser entendido como uma estimativa de desempenho de determinado processo em estudo, contribuindo para o processo de tomada de decisão.

Segundo Takashina (2000), os indicadores devem sempre ser utilizados em áreas de maior criticidade da organização, para que por meio deles seja possível a realização de uma análise crítica dos resultados do processo estudado. Portanto, por meio de indicadores de qualidade é possível monitorar e identificar pontos de melhoria, fazendo com que a gerência consiga alocar recursos na quantidade e momentos corretos, garantindo o fluxo de valor na qualidade de serviço ou produto ofertados ao cliente final.

Meyer (1994) enfatiza a importância da alta administração na participação da definição dos indicadores, como também no gerenciamento e tratamento das informações de nível crítico, pois se- 
gundo o autor, existem empresas que possuem muitos indicadores, todavia são mal gerenciados e desenvolvidos, fazendo com que os mesmos retornem informações não relevantes.

\subsection{IMPORTÂNCIA DO USO DE INDICADORES NA TOMADA DE DECISÃO}

Nos últimos anos o crescimento da globalização e da competitividade do mercado possibilitou às organizações a necessidade de usarem indicadores que possibilitam uma maior visão de desempenho para decidir quais estratégias tomar. 0 maior uso desses indicadores possibilita direcionar as suas mudanças, conhecendo assim a sua posição competitiva e aprimorando os seus processos para melhor prever as decisões futuras (CARREGARO, 2003).

As últimas décadas dispõem de diversos indicadores compostos chamados também de índices que são utilizados pelos gestores para a formulação e a avaliação de políticas públicas de forma a estreitar a ação perante a sociedade e essencial, desde que tenha um nível de planejamento estratégico na implementação dessas políticas para que não haja uma crescente desorganização (PINTO; PEREIRA, 2012).

Os muitos dos atuais sistemas de medição de desempenho não captam os benefícios futuros das iniciativas de melhoria e desenvolvimento ao longo do prazo, sendo assim prejudicial aos resultados, os distorcendo. Assim, tendo em vista o que acontece é necessário instaurar programas de qualidade com os nossos indicadores que serão os nossos guias, muitas vezes a sua aceitação dificulta a decisão (AQUINO, 2001).

O sistema de monitoramento, ou seja, o uso de indicadores poderá levar ao gerente a observação do desempenho de cada etapa do processo e da empresa como um todo, auxiliando assim a identificação onde em determinados momentos deve focar a sua produção para assim garantir ao consumidor um fluxo maior daquela empresa (FERNANDES, 2004).

Ainda, segundo o autor, os indicadores são de extrema importância para o planejamento e controle dos processos, visto que constituem de base do planejamento. Estabelecem parâmetros de verificação do cumprimento de metas e objetivos para assim verificar o rumo da organização, facilitando a ação dos superiores, proporcionando um respaldo maior na tomada de decisão.

\subsection{INDICADOR DE DESEMPENHO DO ATENDIMENTO}

A reclamação, em geral, trata-se de uma queixa do consumidor com a empresa, tornando possível a geração de benefícios tanto para o consumidor, em casos como a troca de um produto defeituoso ou ressarcimento de dinheiro, tanto para empresa, principalmente em relação a credibilidade transmitida e lealdade do consumidor, além disso ela pode ser uma grande fonte de informação para melhoria de um produto/serviço, destacando assim importância de um gerenciamento de reclamações bem sucedido (ROSSI, 2002).

As reclamações podem mudar a satisfação do cliente devido às falhas do sistema e de prestação de serviço, as falhas podem ser corrigidas, existindo uma boa comunicação, para isso melhorar as pessoas diretamente ligadas à entrega dos serviços, tem que seguir as regras de conduta que são essenciais para a melhoria do serviço, além disso aumenta a produtividade para uma melhor percepção do cliente (LOVELOCK; WRIGHT, 2004) 
A ANEEL (2020), com base na resolução n 414/2010, estabelece que as distribuidoras devem emitir relatórios mensais e informar as quantidades de reclamações recebidas, procedentes e improcedentes, além do prazo médio para a resolução de cada uma procedente, garantindo assim um melhor controle de qualidade por parte da agência reguladora, como também da distribuidora.

Ainda de acordo com este autor, as reclamações são rateadas nos seguintes grupos: reclamações por tarifas, custo disponibilidade, faturas, apresentação/entrega de fatura, erro de leitura, variação de consumo, cobrança por irregularidade, prazos, suspensão indevida, cadastro/alteração cadastral, problemas de instalação interna na unidade consumidora, atividades acessórias, indisponibilidade de agência/postos e canais de atendimento/ atendimento telefônico/ serviço de arrecadação e outros.

\section{METODOLOGIA}

O presente artigo configura-se em um estudo sobre os indicadores de desempenho, entre as concessionárias do Nordeste. Trata-se de uma pesquisa documental exploratória de análise de dados históricos e com uma abordagem qualitativa. De acordo com Creswell (1994), uma pesquisa com métodos qualitativos engloba diferentes estratégias, coleta dos dados, estudo e os resultados que ajudem a resolver as questões relacionadas às ciências humanas e sociais.

Inicialmente, a primeira etapa consiste em um estudo por meio de materiais bibliográficos para embasamento teórico, em seguida a partir dos registros disponíveis no site da Agência Nacional de Energia Elétrica (ANEEL), organização que regulamenta as atividades no setor elétrico brasileiro, tornou-se possível realizar um estudo comparativo das quantidade de reclamações recebidas, logo delimitou-se o período de análise de 2015 a 2019, o qual se cogitou por conter elementos atualizados para a presente data.

Segundo Grégoire (2006), os registros de reclamações são uma das importantes formas de avaliar o rendimento, o consumidor espera ter o retorno em serviços do dinheiro investido, dessa forma quando existe alguma insatisfação gera um desequilíbrio no relacionamento. A avaliação é importante para auxiliar ao dirigente na tomada de decisões (OLIVER,1996).

0 tratamento dos dados foi viabilizado por meio do software Microsoft Excel. É importante ressaltar que houve a remoção de valores categorizados como missing, ou seja, foram removidos todos os dados que pudessem comprometer as análises futuras, como por exemplo: células em branco, erros de digitação, caracteres inválidos, entre outros. Após isso, foi utilizado o Microsoft Power B/ de forma a permitir uma melhor visualização e análise mais objetiva dos dados.

Na última etapa abordam-se os indicadores de desempenho. A avaliação da Empresa Equatorial foi relacionada aos índices de maiores reclamações, onde realizou-se um comparativo do somatório das principais reclamações registradas. Além disso, também foi avaliada as reclamações das concessionárias de energia na região Nordeste, onde foi possível visualizar uma média e assim realizar o comparativo de desempenho da região de Alagoas com o Nordeste. 
Figura 1 - Etapas para elaboração da pesquisa

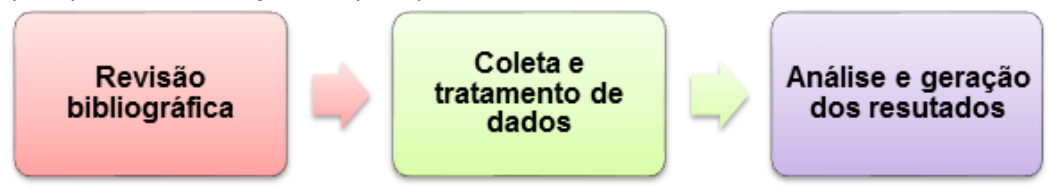

Fonte: Autores (2020).

\section{RESULTADOS E DISCUSSÕES}

Com base nos dados obtidos, foram analisadas as reclamações citadas no tópico 2.4, durante o período analisado de 2015 a 2019, percebe-se um bom desempenho da empresa Equatorial Alagoas em relação à média das concessionárias de energia na região Nordeste. No Gráfico 1, pode-se observar a soma das principais reclamações registradas pela empresa no intervalo dos anos de 2015 a 2019.

Conforme o Gráfico 1, verifica-se que somente a reclamação por cobrança de irregularidade está acima em comparação com média das outras concessionárias, contabilizando 16900 reclamações a mais em relação à média da região Nordeste. É importante destacar que esse tipo de reclamação é derivada de cobranças referentes a irregularidades encontradas no consumo de energia elétrica, identificadas por meio de inspeções.

Gráfico 1 - Comparativo do somatório das principais reclamações registradas entre 2015 e 2019

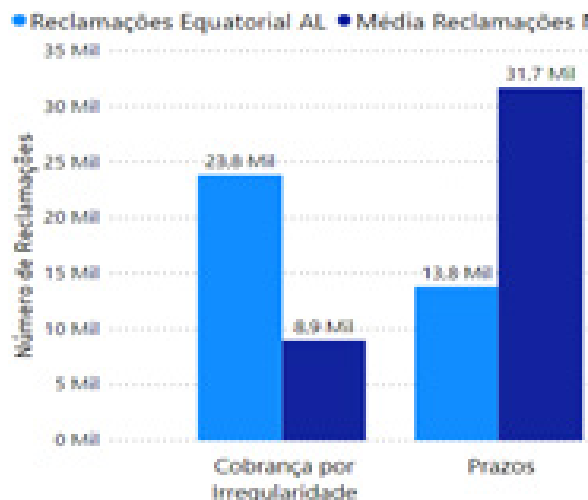

Fonte: Autores (2020).

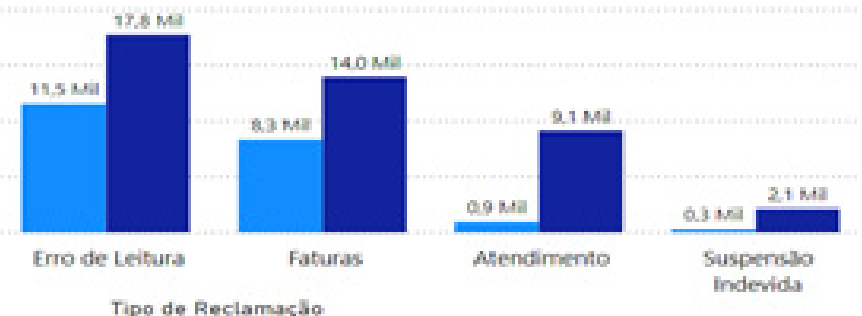

A partir do Gráfico 2, verifica-se o total de reclamações registradas entre os anos de 2015 e 2019. Percebe-se o baixo índice de reclamações comparado às concessionárias dos outros estados, demonstrando assim, um elevado grau de confiabilidade nos serviços, como também, maiores estabilidades na distribuição elétrica e atendimento às necessidades do consumidor. 
Gráfico 2 - Total de todas as reclamações registradas entre os anos de 2015 e 2019

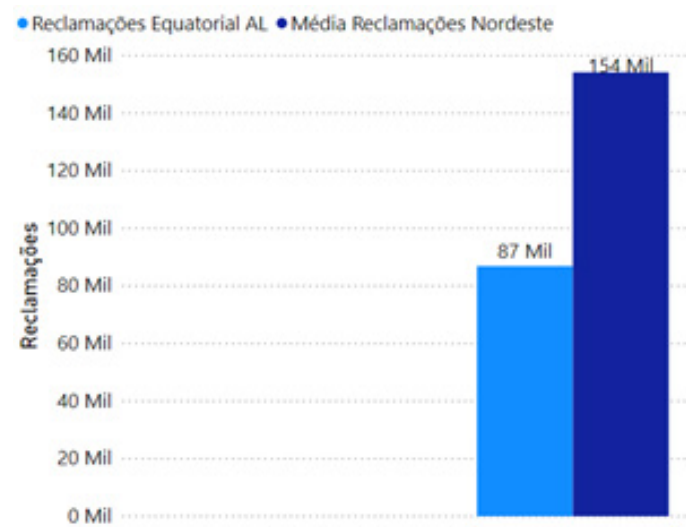

Fonte: Autores (2020).

O Gráfico 3 demonstra que $80 \%$ das reclamações recebidas entre o período analisado, são referentes aos erros de: cobrança por irregularidade, apresentação/entrega de fatura, prazos, erro de leitura e faturas. Desta forma, cabe uma análise mais aprofundada para saber as causas raízes desses problemas e sua representatividade em relação a outras concessionárias da região.

Gráfico 3 - Total de reclamações da Equatorial Alagoas entre 2015 e 2019

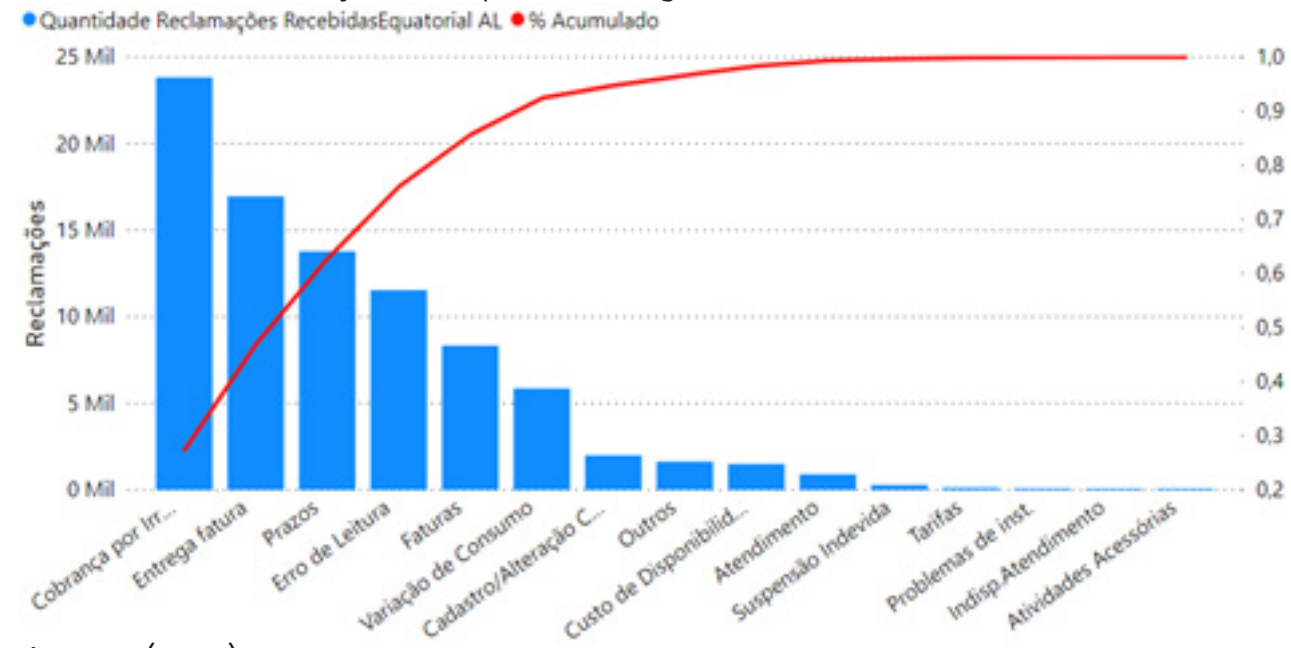

Fonte: Autores (2020).

O Gráfico 4, a seguir, demonstra o elevado número de reclamações a respeito de irregularidades, muitas relacionadas às irregularidades no consumo de energia; é notório que com o passar dos anos 
cria-se um maior controle sobre este tipo de reclamações, tendo em vista a regressão que ocorre desde o ano de 2016, enquanto que a tendência das concessionárias de todo Nordeste é de crescimento.

Gráfico 4 - Comparativo em relação às reclamações de Cobrança de Irregularidades entre 2015 e 2019 - Middia Reclamaçoes Nordeste $\bullet$ Qnt Reclamaçoes Equatorial

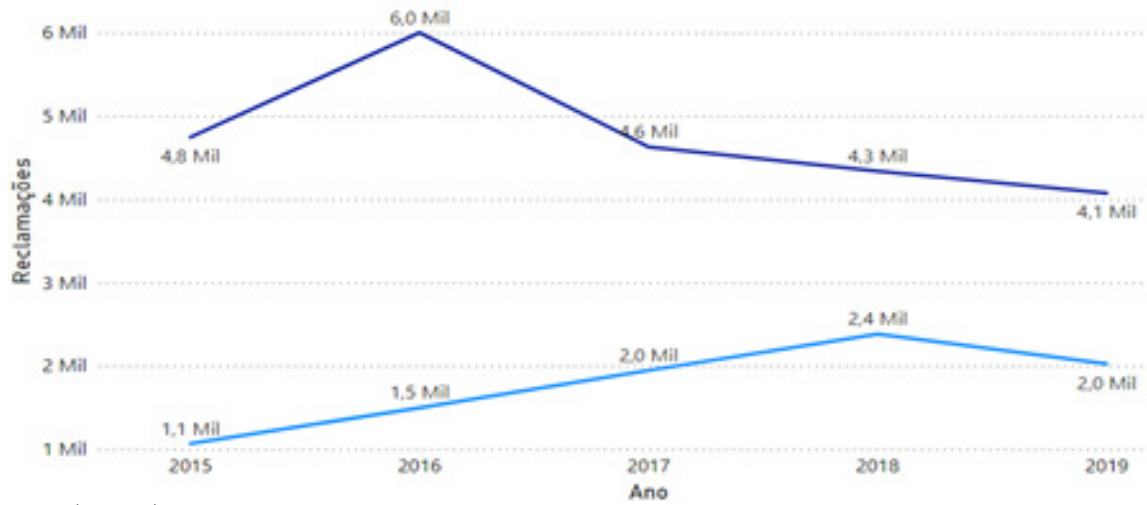

Fonte: Autores (2020).

As reclamações por apresentação/entrega fatura são ocasionadas por erros no processo da distribuição das faturas, seja pelo recebimento em condições irregulares como falta de informações, molhada ou até mesmo pela não entrega.

No Gráfico 5 quantifica-se que ao decorrer dos anos houve quedas e crescimento nesse tipo de reclamação, mantendo até 2018 uma quantidade maior em relação a outras distribuidoras do Nordeste, no ano de 2019 houve um grande crescimento tanto na Equatorial Alagoas como nas concessionárias do Nordeste, porém esta última houve um grande crescimento na qual mais que triplicou a quantidade de reclamações em relação ao ano anterior.

Gráfico 5 - Comparativo em relação às reclamações de Apresentação/Entrega Fatura entre 2015 e 2019 - Média Reclamaçoes Nordeste • Cnt Reclamaçoes Equatorial

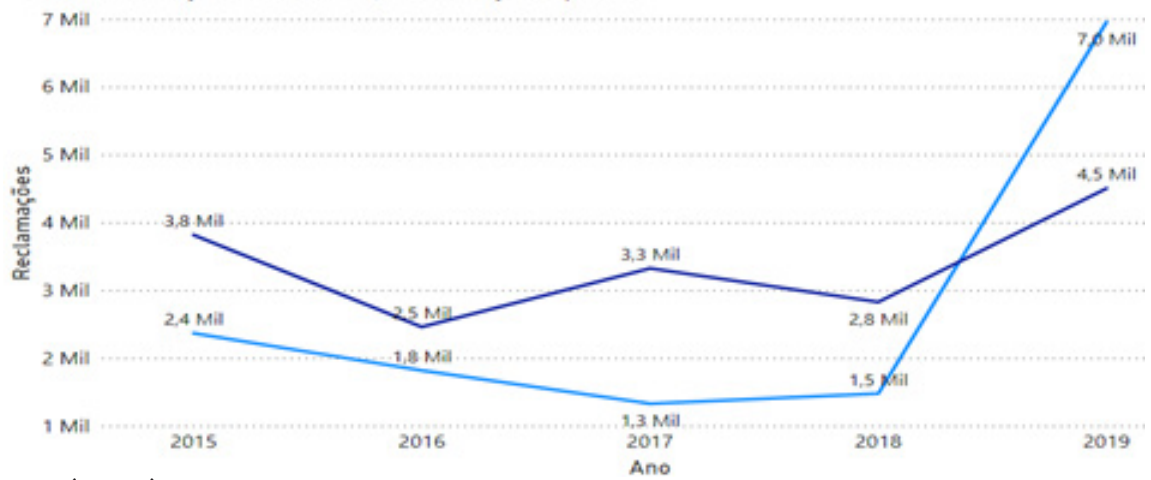

Fonte: Autores (2020). 
Nos Gráficos 6 e 7, percebe-se que o número de erros de leitura e de fatura da Equatorial AL, durante os anos de 2015 e 2018, estava abaixo da média registrada em todo Nordeste, porém, nos anos posteriores há um aumento muito repentino no número de reclamações. Uma possível causa seria a troca de gestão da concessionária de energia em Alagoas, onde segundo a Rocha (2020), a nova gestão foi responsável por terceirizar maior parte de seus serviços. Desta forma, cabe aos gestores da empresa melhor capacitarem seus terceirizados de modo a controlar o número de possíveis erros técnicos na prestação de serviços.

Gráfico 6 - Comparativo em relação aos erros de leitura entre 2015 e 2019 - Média Reclamaçoes Nordeste - Ont Reclamaçoes Equatorial

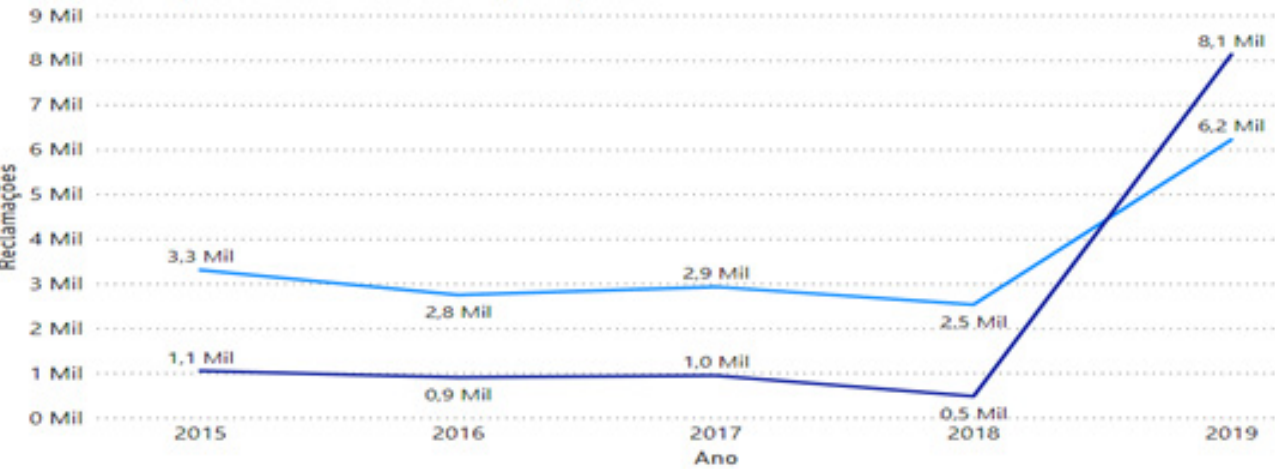

Fonte: Autores (2020).

Gráfico 7 - Comparativo em relação às reclamações de fatura entre 2015 e 2019

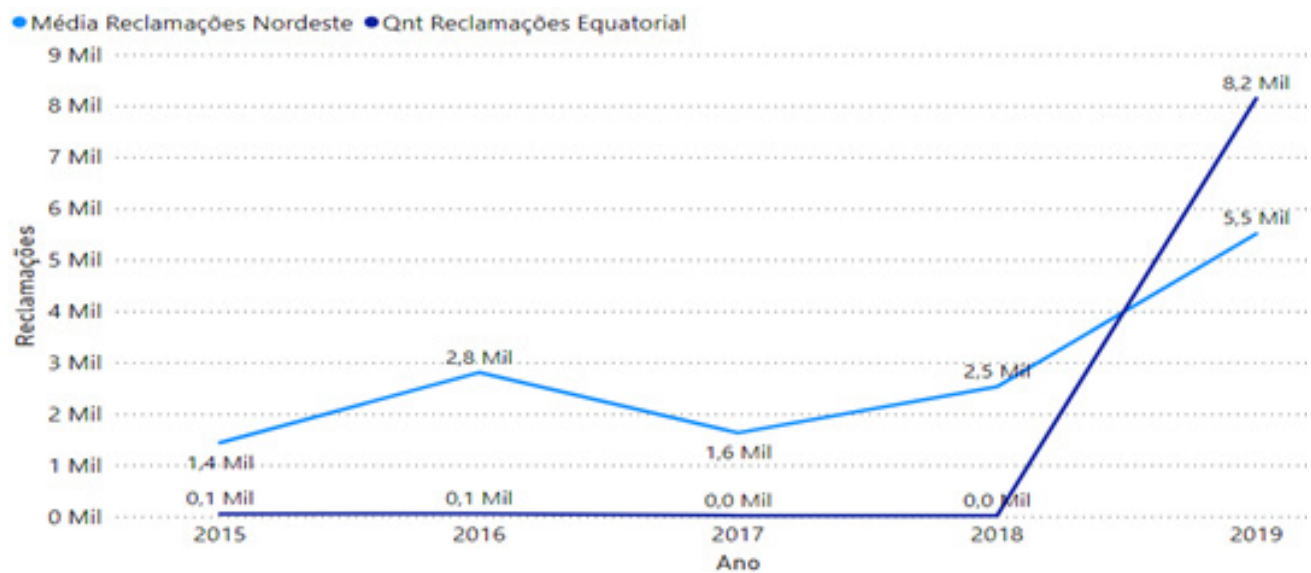

Fonte: Autores (2020).

As reclamações por prazos, representadas no Gráfico 8, são determinadas por serviços que estão fora do tempo estabelecido pela concessionária ou pela agência reguladora do setor, um fator 
importante é que elas são derivadas principalmente por outros tipos reclamações, por exemplo erro de leitura, em termos quantitativos observa-se queda na quantidade desse tipo de reclamação como também que ela se encontra bem abaixo da média das outras concessionárias do nordeste, esta última, tendendo a constância aproximada em sua quantidade.

Gráfico 8 - Comparativo entre reclamações referente a prazos entre 2015 e 2019

- Qnt Reclamaçōes Equatorial - Média Reclamaçōes Nordeste

$8 \mathrm{Mil}$

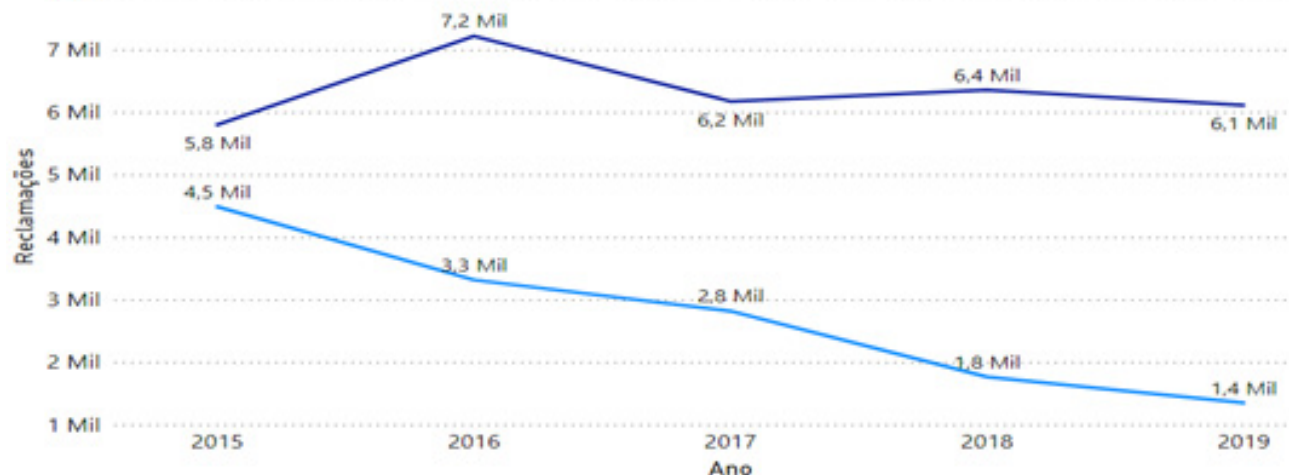

Fonte: Autores (2020).

\section{CONSIDERAÇÕES FINAIS}

Conforme observado, os resultados obtidos mostram grande variabilidade, pela concessionária de Alagoas, no número de reclamações a partir do ano de 2019 quando comparado com os anos antecessores, este fato se deve pela troca da empresa responsável pelo atendimento do local, deste modo a forma de operação no Estado tem sido modificada, o que poderia ter gerado essas discrepâncias nos gráficos.

Foi possível verificar o nível de atendimento da concessionária de Alagoas, em comparação com organizações regionais semelhantes e a variação deste critério, permitindo o estabelecimento de indicadores que possibilitem o apoio à tomada de decisão gerencial na melhoria do nível de serviço da concessionária.

Apesar do fato de que em alguns indicadores analisados a Equatorial Alagoas fica acima da média do Nordeste, em comparação com os anos anteriores e gerências diferentes, no ano de 2019 houve apenas 1 dos 9 indicadores em que o valor se manteve, em todos os outros foram identificados acréscimos, impactando no aumento significativo nas médias de reclamação encontradas no ano de entrada da nova concessionária.

Identificou-se, ainda, o desempenho da concessionária após a mudança de gestão da prestadora de serviço elétrico de Alagoas, sendo assim é possível realizar novos estudos, visando entender o que será necessário para a melhoria de seu desempenho. Como estudo futuro, sugere-se um aprofunda- 
mento na investigação de causas destes indicadores e o diagnóstico de meios eficientes de correções deles, como forma de incrementar a competitividade da empresa e a satisfação da população assistida pelos seus serviços.

\section{REFERÊNCIAS}

ANEEL - Agência Nacional de energia elétrica. Por dentro da conta de luz: Informação de utilidade pública. 7 ed., 2016.

AQUINO, André Carlos Busanelli. Sistema de apoio ao processo decisório: a gestão econômica utilizando indicadores balanceados nas decisões estratégicas e de longo prazo. São Carlos, 2001. Dissertação (Mestrado em Engenharia de Produção) - Escola de Engenharia de São Carlos, Universidade de São Paulo, São Paulo, 2001.

CARREGARO, José Carlos. Proposta de indicadores de desempenho às distribuidoras de energia federalizadas do setor elétrico brasileiro. 2003. Dissertação (Mestrado em Engenharia de Produção) - Universidade Federal de Santa Catarina, Florianópolis-SC, 2003.

CRESWELL, J. W. Research design: qualitative \& quantitative approaches. London: Sage, 1994

FALCÃO, A. W. S.; NUNES, R. V.; ASSIS, C. W. C.; ADRIANO, N. A.; SIEBRA, A. A. Os reflexos da crise hídrica brasileira na estrutura de custos das empresas do setor de energia elétrica. ABCustos, São Leopoldo: Associação Brasileira de Custos, v. 14, n. 2, p. 1-35. 2019

FERNANDES, Djair Roberto. Uma contribuição sobre a construção de indicadores e sua importância para a gestão empresarial. Revista da FAE, 2004. Disponível em: https://revistafae.fae.edu/ revistafae/article/view/430/326. Acesso em: 4 abr. 2020.

GRÉGOIRE, Y.; FISHER, R. J. Os efeitos da qualidade do relacionamento na retaliação do cliente. Cartas de Mercado, v. 17, n. 1, p. 31-46, 2006.

IBGE - Instituto Brasileiro de Geografia e Estatística. Resultados preliminares do universo do Censo Demográfico 2010 - Domicílios particulares permanentes, por existência de energia elétrica, segundo as Grandes Regiões e as Unidades da Federação. 2010. Disponível em: https://censo2010. ibge.gov.br/sinopse/index.php?dados=P13\&uf=00. Acesso em: 12 jun. 2020.

LEITE, N., DELGADO, M., HAGE, F. Os desafios de armazenamento de energia no setor eletrico. Boletim Energético, Fundação Getulio Vagas, 2017. 
LOVELOCK, WRIGHT, C.; L. Serviços: marketing e gestão. São Paulo, Saraiva, 2004.

MEYER, Christopher. How the right measures help teams excel. Business review, Boston-Harvard, p. 94-103, maio/jun. 1994.

OLIVER, R. L. Medição e avaliação de processos de satisfação-Retailing Settings. Journal of Retailing, v. 57, n. 3,1981.

PEREIRA, Danielle Ramos; PINTO, Marcelo Rezende. A importância do entendimento dos indicadores na tomada de decisão de gestores públicos. Revista de serviços públicos. Disponível em: https://repositorio.enap.gov.br/bitstream/1/1779/1/A\%20import\%c3\%a2ncia\%20do\%20 entendimento\%20dos\%20indicadores\%20na\%20tomada\%20de\%20decis\%c3\%a30\%20de\%20 gestores\%20p\%c3\%bablicos.pdf. Acesso em: 1 abr. 2020.

REGO, Erik Eduardo. Proposta de aperfeiçoamento da metodologia dos leilões de comercialização de energia elétrica no ambiente regulado: aspectos conceituais, metodológicos e suas aplicações. 2012. 232 f. Tese (Doutorado em Ciências) - Universidade de São Paulo, São Paulo, 2012.

ROMERA, Roberto Saraiva. Análise do novo modelo do setor elétrico a partir de 2003. 2005. $129 \mathrm{f}$. Monografia (Bacharelado em Ciências Econômicas) - Centro Universitário Fundação Santo André, Santo André, 2005.

SANTOS, Cristiane Pizzutti dos; ROSSI, Carlos Alberto Vargas. O Impacto do gerenciamento de reclamações na confiança e na lealdade do consumidor. Rev. adm. contemp., Curitiba, v. 6, n. 2, p. 49-73, ago. 2002.

TAKASHINA, Newton Tadachi. Indicadores da qualidade e do desempenho: como estabelecer metas e atingir resultados. Rio de Janeiro: Qualitymark, 1996.

TOLMASQUIM, Mauricio Tiomno. Perspectivas e planejamento do setor energético no Brasil.

Estud. av., São Paulo, v. 26, n. 74, p. 247-260, 2012. Disponível em http://www.scielo.br/scielo. php?script=sci_arttext\&pid=S0103-40142012000100017\&lng=en\&nrm=iso. Acesso em: 25 maio 2020. 
1 Graduação em Engenharia de Produção - Centro Universitário Tiradentes (UNIT).

2 Graduação em Engenharia de Produção - Centro Universitário Tiradentes (UNIT) e Engenharia da Computação (UFAL).

3 Graduação em Engenharia de Produção - Centro Universitário Tiradentes (UNIT).

4 Graduação em Engenharia de Produção - Centro Universitário Tiradentes (UNIT).

5 Graduação em Engenharia de Produção - Centro Universitário Tiradentes (UNIT).

6 Graduação em Engenharia de Produção - Centro Universitário Tiradentes (UNIT).

7 Danielle Freitas Santos Marinho - Mestre em Engenharia de Produção - UFPE. Engenheira de Segurança do TrabaIho - FIC. Engenheira de Produção - UFCG. Administradora - UFCG.

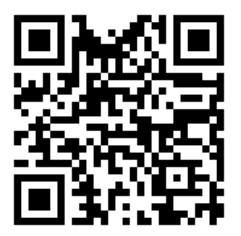

A autenticidade desse artigo pode ser conferida no site https://periodicos. set.edu.br

\section{(c) (i) (2)}

Este artigo é licenciado na modalidade acesso abertosob a Atribuição-Compartilhalgual CC BY-SA
GRUPO TIRADENTES Inspirando ofuturo

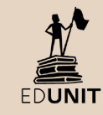

